\title{
HIV-1 Vpr Causes Neuronal Apoptosis and In Vivo Neurodegeneration
}

\author{
Gareth J. Jones, ${ }^{1 *}$ Nicola L. Barsby, ${ }^{2,3 *}$ Éric A. Cohen, ${ }^{4}$ Janet Holden, ${ }^{5}$ Kim Harris, ${ }^{3}$ Peter Dickie, ${ }^{2}$ Jack Jhamandas, ${ }^{3}$ and \\ Christopher Power ${ }^{1,2,3}$ \\ ${ }^{1}$ Department of Clinical Neurosciences, University of Calgary, Calgary, Alberta, Canada T2N 4N1, Departments of ${ }^{2}$ Medical Microbiology and Immunology \\ and ${ }^{3}$ Medicine, University of Alberta, Edmonton, Alberta, Canada T6G 2S2, ${ }^{4}$ Institut de Recherches Cliniques de Montréal and Department of Microbiology \\ and Immunology, University of Montreal, Montreal, Quebec, Canada H2W 1R7, and 5Department of Pathology, St. Paul's Hospital, Vancouver, British \\ Columbia, Canada V6Z 1 Y6
}

Despite the introduction of highly active antiretroviral therapy, dementia caused by human immunodeficiency virus-1 (HIV-1) infection remains a devastating and common neurological disorder. Although the mechanisms governing neurodegeneration during HIV-1 infection remain uncertain, the HIV-1 accessory protein, viral protein R (Vpr), has been proposed as a neurotoxic protein. Herein, we report that Vpr protein and transcript were present in the brains of HIV-infected persons. Moreover, soluble Vpr caused neuronal apoptosis, involving cytochrome $c$ extravasation, p53 induction, and activation of caspase-9 while exerting a depressive effect on whole-cell currents in neurons $(p<0.05)$, which was inhibited by iberiotoxin. Vpr-activated glial cells secreted neurotoxins in a concentration-dependent manner $(p<0.001)$. Transgenic ( $\mathrm{Tg})$ mice expressing Vpr in brain monocytoid cells displayed the transgene principally in the basal ganglia $(p<0.05)$ and cerebral cortex $(p<0.01)$ compared with hindbrain expression. Vpr was released from cultured transgenic macrophages, which was cytotoxic to neurons and was blocked by anti-Vpr antibody $(p<0.05)$. Neuronal injury was observed in Tg animals compared with wild-type littermates, chiefly affecting GAD65 $(p<0.01)$ and vesicular acetylcholine transferase $(p<0.001)$ immunopositive neuronal populations in the basal ganglia. There was also a loss of subcortical synaptophysin $(p<0.001)$ immunoreactivity as well as an increase in activated caspase-3, which was accompanied by a hyperexcitable neurobehavioral phenotype $(p<0.05)$. Thus, HIV-1 Vpr caused neuronal death through convergent pathogenic mechanisms with ensuing in vivo neurodegeneration, yielding new insights into the mechanisms by which HIV-1 injures the nervous system.

Key words: Vpr; HIV-1; dementia; transgenic mouse; apoptosis; neuron

\section{Introduction}

Human immunodeficiency virus-1 (HIV-1)-associated dementia (HAD) is a subcortical dementia, defined by motor, behavioral, and cognitive abnormalities arising because of neuronal damage and death (McArthur et al., 2005). HIV-1 enters the CNS early in the course of disease (Resnick et al., 1988; Spector et al., 1993) and establishes productive infection in the brain, detectable in perivascular macrophages and microglia. Despite the absence of productive infection of neurons, HIV-1 infection is associated with neuronal loss in distinct regions of the brain, including the frontal cortex, substantia nigra, cerebellum, and striatum (Everall et al., 1993). Although necrosis of neurons has been demonstrated, it has been reported that the neuronal loss

\footnotetext{
Received Sept. 29, 2006; accepted Feb. 5, 2007.

This work was supported by the Canadian Institutes for Health Research (CIHR). G.J.J. holds a CIHR Fellowship: E.A.C., J.J., and C.P. hold Canada Research Chairs (Tier 1) in Human Retrovirology, Neurodegenerative Diseases, and Neurological Infection and Immunity, respectively; and C.P. is an Alberta Heritage Foundation for Medical Research Senior Scholar.

*G.J.J. and N.L.B. contributed equally to this work.

Correspondence should be addressed to Dr. Christopher Power, Department of Medicine, University of Alberta, 6-11 Heritage Medical Research Centre, Edmonton, Alberta, Canada T6G 2S2. E-mail: chris.power@ualberta.ca. DOI:10.1523/JNEUROSCI.5522-06.2007

Copyright $\odot 2007$ Society for Neuroscience $\quad$ 0270-6474/07/273703-09\$15.00/0
}

observed in HIV-1-infected patients is also attributable to apoptosis (Adle-Biassette et al., 1995; Gelbard et al., 1995; An et al., 1996). The underlying mechanisms of HIV-induced neuropathogenesis remain uncertain, but it is clear that both HIV-1 encoded proteins and neurotoxic host molecules secreted by activated glia in response to HIV-1 infection or activation contribute to neuronal cell death (for review, see Jones and Power, 2006).

The HIV-1 accessory protein viral protein $\mathrm{R}(\mathrm{Vpr})$ is synthesized late in the HIV-1 life cycle, packaged into the virion, and is essential for HIV-1 replication in macrophages (Emerman, 1996; Subbramanian et al., 1998). In addition, studies from numerous groups have demonstrated that HIV-1 Vpr mediates multiple cellular functions, including nuclear import of the HIV-1 preintegration complex (Popov et al., 1998), $\mathrm{G}_{2}$ cell cycle arrest (He et al., 1995; Emerman, 1996), transactivation of both viral replication and host genes (Cohen et al., 1990; Yao et al., 1998), and induction of cellular apoptosis (Yao et al., 1998; Stewart et al., 2000). Indeed, soluble HIV-1 Vpr protein is detected in the CSF and serum of HIV-1-infected patients with neurological disorders (Levy et al., 1994). Furthermore, several lines of evidence suggest that HIV-1 Vpr might be a potential toxic molecule mediating neuronal cell death during HIV-1 infection, albeit at high concentrations ( $>2 \mu \mathrm{M}$ ) (Piller et al., 1998; Sabbah and Roques, 
2005). In vitro studies of cultured rat hippocampal neurons (Piller et al., 1998; Huang et al., 2000), rat cortical and striatal neurons (Sabbah and Roques, 2005), or human neuronal cell lines (Patel et al., 2000, 2002) have revealed that HIV-1 Vpr might cause neuronal apoptosis. Given the uncertainty regarding the neuropathogenic properties of HIV-1 Vpr and moreover its in vivo effects, we investigated the mechanisms by which HIV-1 Vpr influenced neuronal viability using both in vitro and in vivo models.

\section{Materials and Methods}

Vpr preparation. The procedure for producing full-length recombinant HIV-1 Vpr protein derived from pNL4-3 has been described previously (Levy et al., 1994). Briefly, Vpr was produced after infection of high five insect cells $\left(2 \times 10^{9}\right.$ cells per liter of culture infected at a multiplicity of infection of 5-10) with recombinant baculovirus encoding the HIV-1 NL4-3 vpr open-reading frame fused to a His-tag at the $\mathrm{N}$ terminus. The Vpr baculovirus vector was kindly provided by Dr. Ned Landau (The Salk Institute for Biological Studies, La Jolla, CA). Vpr preparations that were over $90 \%$ pure were routinely obtained. Fractions containing $\mathrm{Vpr}$ were dialyzed against three changes of 100 volumes of PBS, aliquoted, and store at $-80^{\circ} \mathrm{C}$. The yield of recombinant Vpr obtained by this method was $1 \mathrm{mg}$ per liter of high five cell culture.

Cell cultures. LAN-2 (human cholinergic neuroblastoma), U-937 (human monocytoid), and U373 (human astrocytic) cell lines were cultured as described previously (Zhang et al., 2003). Before use, LAN-2 cells were differentiated for $3 \mathrm{~d}$ in L-15 medium (Sigma-Aldrich, Oakville, Ontario, Canada) containing 10\% FBS and $1 \mathrm{~mm}$ dibutyryl-cAMP, whereas U-937 cells were differentiated for $2 \mathrm{~d}$ with $50 \mathrm{ng} / \mathrm{ml}$ phorbol 12-myristate 13 acetate (PMA; Sigma-Aldrich). Mouse bone-marrow derived macrophages were isolated from the pelvis and femurs of mice using culture methods described previously (Tsutsui et al., 2004). Rat fetal neurons (RFNs) were isolated from the septum of 17- and 18-d-old Sprague Dawley rat fetuses (Charles River, Saint-Constant, Quebec, Canada) by methods described previously (Jhamandas and MacTavish, 2004) following approved protocols set out by the local Health Sciences Animal Policy and Welfare Committee. Human fetal neurons (HFNs) were isolated from 15- to 19-week-old aborted fetuses and cultured by methods described previously (Power et al., 1998), supported by local ethics committees.

Immunohistochemistry and immunofluorescence. Paraffin-embedded 5 $\mu \mathrm{m}$ brain sections from HIV-1 seropositive and seronegative patients and mice after neurobehavioral studies were immunostained with antibodies to HIV-1 Vpr [diluted 1:200; rabbit polyclonal raised against bacterially expressed recombinant Vpr (Lavallee et al., 1994)], CD45 (diluted 1:25; Zymed, San Francisco, CA), Iba-1 (diluted 1:100; Wako Chemicals, Neuss, Germany), and F4/80 (1:100; Serotec, Indianapolis, IN) for macrophage and microglia detection, neuronal-specific nuclear protein (NeuN) (diluted 1:200; Chemicon, Temecula, CA) for neuron detection, and cleaved caspase-3 for detection of activated caspase-3 (1: 100; Cell Signaling Technology, Beverly, MA). Immunostaining protocols for single and double labeling were performed, as reported previously (Tsutsui et al., 2004). For immunohistochemical staining, sections were stained with $\mathrm{DAB}$ and 5-bromo-4-chlor-indolyl-phosphate (BCIP) while immunofluorescent sections were stained with goat anti-mouse and goat anti-rabbit Alexa Fluor 488 (Invitrogen, Eugene, OR), goat anti-rat FITC (Serotec), and goat anti-rabbit Cy3 (Jackson ImmunoResearch, West Grove, PA) secondary antibody followed by washing and mounting in gelvatol and acrytol for immunofluorescence and immunohistochemistry, respectively.

Direct and indirect neurotoxicity assays. For the direct neurotoxicity assay, differentiated LAN-2 cells or RFNs were cultured in 96-well flat bottom plates in serum-free AIM-V media (Sigma-Aldrich) with and without different concentrations of HIV-1 Vpr for up to $48 \mathrm{~h}$. In some experiments, HIV-1 Vpr-specific antibodies (1:100 dilution) were included in the culture. After the culture period, cells were fixed with $4 \%$ formalin, washed in PBS containing 0.1\% Triton X-100 (Sigma-Aldrich), and blocked for $90 \mathrm{~min}$ at $4^{\circ} \mathrm{C}$ with LI-COR Odyssey Blocking Buffer
(LI-COR, Lincoln, NE). After removal of the blocking reagent, the cells were incubated overnight at $4^{\circ} \mathrm{C}$ with mouse anti- $\beta$-tubulin $(1: 600$ dilution; Sigma-Aldrich) and either rabbit anti-cleaved caspase-3 (C-Casp-3, 1:100 dilution; Cell Signaling Technology) or rabbit anti-p53 (1:100 dilution; Santa Cruz Biotechnology, Santa Cruz, CA). After primary antibody application, the cells were washed in PBS containing $0.1 \%$ Tween 20 and incubated with either goat anti-mouse Alexa Flour 680 (1:200 dilution; Invitrogen) or goat anti-rabbit IRDye 800CW (1:800 dilution; Rockland Immunochemicals) secondary antibodies. All antibody dilutions were made with LI-COR Odyssey Blocking Buffer. After removal of the secondary antibodies, the cells were washed in PBS/0.1\% Tween 20 and left to dry in the dark before quantification of $\beta$-tubulin, active caspase-3, and p53 immunoreactivity using the Odyssey Infrared Imaging System (LI-COR). Active caspase-3 and p53 immunoreactivity were normalized to the $\beta$-tubulin expression and then expressed relative to controls. For the indirect neurotoxicity assay, U373 cells and PMAdifferentiated U-937 cells were cultured in serum-free AIM-V media with and without HIV-1 $\operatorname{Vpr}(0.1,1.0,10.0$, and $100.0 \mathrm{~nm})$ for $48 \mathrm{~h}$, after which cell culture supernatants were harvested and cleared of cellular debris by low-speed centrifugation. In addition, supernatants were also removed from mouse macrophage cultures. These conditioned media (CM) were then applied in the presence or absence of HIV-1 Vpr-specific antibodies (1:100 dilution) to differentiated LAN-2 cells or RFNs as described previously (Zhang et al., 2003). After $48 \mathrm{~h}$ of exposure, neuronal viability was quantified by $\beta$-tubulin immunoreactivity (as described above).

Human brain samples. Autopsied frozen and fixed brain tissue (frontal lobe) from HIV-1 B clade seropositive (all were acquired immunodeficiency syndrome-defined) and seronegative individuals, collected with consent and stored in the Laboratory for Neurological Infection and Immunity Brain Bank were used for RNA extraction for real-time PCR and immunohistochemistry, respectively, as described previously (Johnston et al., 2000; Tsutsui et al., 2004).

Neurophysiology studies. Whole-cell recordings were obtained from acutely dissociated neurons of rat septal nucleus, the diagonal band of Broca, as described previously (Jassar et al., 1997; Jhamandas et al., 2001). Briefly, whole-cell currents were activated by voltage steps or ramp protocol from a holding potential of $-80 \mathrm{mV}$. All drugs including $\mathrm{Vpr}$ were applied via bath perfusion. $\mathrm{Ca}^{2+}$-dependent $\mathrm{K}^{+}$conductance was isolated using the $\mathrm{BK}$ channel-specific blocker iberiotoxin. Biophysical separation of $I_{\mathrm{A}}$ (transient outward $\mathrm{K}^{+}$currents) from $I_{\mathrm{K}}$ (delayed rectifier $\mathrm{K}^{+}$currents) were achieved by adding hyperpolarizing prepulse voltage step protocols that activate $I_{\mathrm{A}}$ and $I_{\mathrm{K}}$, whereas activation of $I_{\mathrm{K}}$ alone was achieved by voltage steps from $-40 \mathrm{mV}$ to more depolarized levels. Thus, subtraction of the two protocols yielded $I_{\mathrm{A}}$.

Mitochondrial membrane potential, cytochrome c release, and caspase- 9 studies. Mitochondrial membrane potentials in HIV-1 Vpr-treated LAN-2 cells were analyzed using the MitoProbe DiIC ${ }_{1}(5)$ Assay kit for Flow Cytometry (Invitrogen) following the manufacturer protocol. DiIC $_{1}(5)$ staining was quantified using a FACScan flow cytometer (BD Biosciences, Franklin Lakes, NJ), where loss of mitochondrial membrane permeability was accompanied by a reduction in the intensity of $\mathrm{DiIC}_{1}(5)$ staining, and the results are expressed as the percentage of LAN-2 cells showing diminished $\operatorname{DiIC}_{1}(5)$ staining. Cytochrome $c$ release in HIV-1 Vpr-treated LAN-2 cells was analyzed with the Cytochrome $c$ Releasing Apoptosis Assay kit (BioVision Research Products, Mountain View, CA) following the manufacturer protocol. Protein $(10 \mu \mathrm{g})$ from LAN-2 cell cytosolic and mitochondrial fractions was separated by $12 \%$ SDS-PAGE, transferred onto nitrocellulose membranes, and probed with mouse anti-cytochrome $c$ (1:200 dilution; BioVision Research Products). Goat anti-mouse secondary antibody conjugated to HRP (1:2000 dilution; Chemicon) was used to detect the primary antibody bound to the protein using chemiluminescence (Roche Diagnostics, Laval, Quebec, Canada). Caspase- 9 activity in HIV-1 Vpr-treated LAN-2 cells was quantified with the Caspase-9/Mch6 Colorimetric Assay kit (BioVision Research Products) following the manufacturer protocol.

Western blotting. Differentiated LAN-2 cells were cultured with or without HIV-1 Vpr for up to $6 \mathrm{~h}$, after which cells were lysed in lysis buffer [20 mu Tris, $1 \% \mathrm{NP}-40,50 \mathrm{~mm} \mathrm{NaCl}$, protease inhibitors (1:1000; 
A

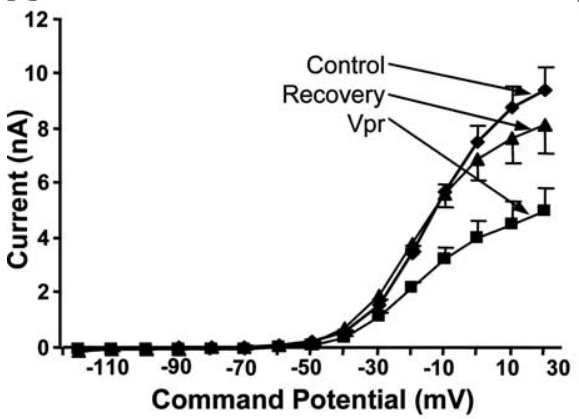

C

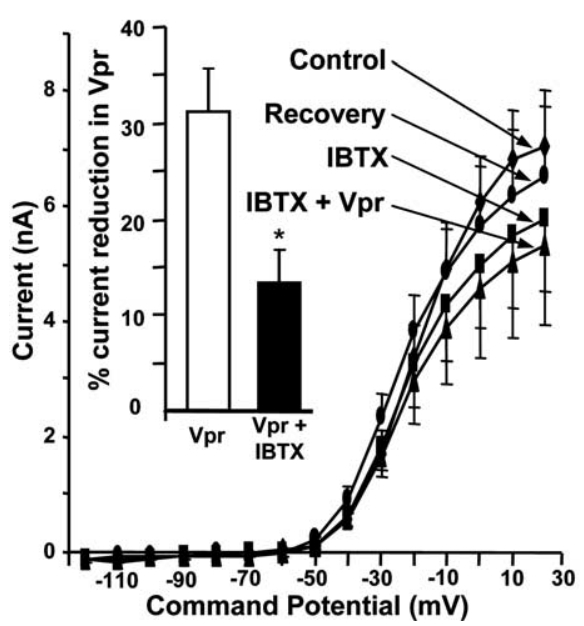

Figure 1. HIV-1 Vpr modulates neuronal membrane responses. $\boldsymbol{A}$, Whole-cell currents were reduced in acutely dissociated rat basal forebrain neurons ( $n=9$ cells) after treatment with soluble HIV- $1 \operatorname{Vpr}(10 \mathrm{nM})$. B, Concentration-response relationship for HIV-1 Vpr showing a reduction of whole-cell currents ( $n=4-9$ cells at each concentration). C, HIV-1 Vpr-mediated reduction in whole-cell current was blocked in the presence of $25 \mathrm{~nm}$ iberiotoxin (histograms in inset represents 5 cells). D, HIV-1 Vpr (10 nM) reduced the delayed rectifier $\left(I_{K}\right)$ potassium current (top) but not the transient outward $\left(I_{A}\right)$ potassium current (bottom). Insets show voltage protocols used to identify $I_{\mathrm{K}}$ and $I_{\mathrm{A}} \cdot I_{\mathrm{A}}$ obtained from subtracting currents derived with the two voltage protocols is shown $\left({ }^{*} p<0.01\right)$. Ctrl, Control.

Protease Inhibitor cocktail set III; Calbiochem, La Jolla, CA), serine phosphatase inhibitor, $1 \mu \mathrm{M}$ okadaic acid (Chemicon), and $0.5 \mathrm{~mm}$ EDTA]. Protein lysates were also prepared from the brains of Vpr transgenic (Tg) and wild-type (Wt) animals. Protein lysates were separated by $10 \%$ SDS-PAGE, and the membrane was blotted for phosphorylated Akt (1:1000; Cell Signaling Technology), total Akt (1:000; Cell Signaling Technology), phosphatidyl inositol 3-kinase (PI3K) (1:500; Cell Signaling Technology), GAD65 (1:1000; Chemicon), synaptophysin (1:1000; Santa Cruz Biotechnology), vesicular acetylcholine transferase (VAChT) (1:1000; Sigma), C-Casp-3 (1:250; Cell Signaling Technology), and $\beta$-actin (1:1000; Santa Cruz Biotechnology). Ratios of Western blot immunoreactivity in wild-type and $\mathrm{Vpr}$-Tg mice relative to $\beta$-actin were quantified by densitometry using Scion (Frederick, MD) imaging software.

Real-time reverse transcription-PCR. Six hours after HIV-1 Vpr stimulation, U373 cells and U-937 cells were washed with PBS and lysed in TRIzol (Invitrogen, Gaithersburg, MD), and genomic RNA was isolated in accordance with the manufacturer guidelines, as was the RNA from Vpr-Tg and Wt brains. Genomic RNA was dissolved in DEPC-treated water and used for the synthesis of cDNA. The primers used in the real-time PCR were as follows: glyceraldehyde-3-phosphate dehydrogenase (GAPDH); human interleukin (IL)- $1 \beta$, forward primer 5 '-CCA AAG AAG AAG ATG GAA AAG CG-3' and reverse primer $5^{\prime}$-GGT GCT GAT GTA CCA GTT GGG-3' [melting temperature (Tm), 58]; human IL-6 (Jones et al., 2005); mouse tumor necrosis factor- $\alpha$ (TNF- $\alpha$ ) (Overbergh et al., 1999), mouse IL- $1 \beta$, forward primer 5 '-CAA CCA ACA AGT GAT ATT CTC CAT G-3' and reverse primer 5'-GAT CCA CAC TCT
CCA GCT GCA-3' (Tm, 60 $\left.{ }^{\circ} \mathrm{C}\right)$; mouse IL-6, forward primer $5^{\prime}$-caa cca cgg cct tcc cta ct- $3^{\prime}$ and reverse primer $5^{\prime}$-tca ttt cca cga ttt ccc aga g-3' (Tm, 54); mouse F4/80, forward primer $5^{\prime}$-gcc acc tgc act gac acc- $3^{\prime}$ and reverse primer $5^{\prime}$-gct gca ctt ggc tct cc-3' (Tm, 54); mouse GFAP, forward primer $5^{\prime}$-gga cat cga gat cgc cac cta cag- $3^{\prime}$ and reverse primer $5^{\prime}$-ctc acc atc ccg cat ctc cac agt- $3^{\prime}$ (Tm, 58), HIV-Vpr NL43 outer forward primer $5^{\prime}$-aga gga cag atg gaa caa gcc- $3^{\prime}$ and outer reverse primer $5^{\prime}$-cta gtc tag gat cta ctg gct cc-3' (Tm, 60), and HIV-Vpr NL43 inner forward primer $5^{\prime}$-gac act aga gct ttt aga gg- $3^{\prime}$ and inner reverse primer $5^{\prime}$-gga taa aca gca gtt gtt gca g-3' (TM, 57). Semiquantitative analysis was performed by monitoring in real time the increase in the fluorescence of the SYBR-green dye (Invitrogen) on a Bio-Rad (Hercules, CA) i-Cycler. Real-time fluorescence measurements were performed, and a threshold cycle value for each gene of interest was determined as reported previously (Power et al., 2003). All data were normalized against the GAPDH mRNA level and expressed as relative fold change to the unstimulated control.

In vivo mouse model. Vpr transgenic mice were generated as described previously (Dickie et al., 2004) in which $v p r$ was under the control of the $c$-fms (M-CSF receptor) promoter, permitting expression chiefly in monocytoid cells. Four-month-old Vpr transgenic and littermate wild-type mice were subjected to three behavioral tests: the inverted screen test at 20 and $40 \mathrm{~cm}$ and the horizontal bar test as described previously (Guenther et al., 2001). The Z-score and mean deficit score was measured for each animal and averaged using previously described calculations (Heseltine et al., 1998). Brains from these animals were then harvested and stored for immunohistochemistry, reverse transcription (RT)-PCR, and Western blot studies.

\section{Results}

HIV-1 Vpr modulates neuronal membrane responses

Previous studies showed that higher concentrations of Vpr exerted variable electrophysiological effects on neurons (Piller et al., 1998). To define the precise pathophysiological actions of $\mathrm{Vpr}$ on neuronal membrane activity, we examined the current-voltage relationship in dissociated rat septal neurons, indicating that $\operatorname{Vpr}(10 \mathrm{~nm})$ caused a reduction in outward whole-cell currents in the voltage range from -30 to $+3 \mathrm{mV}$ (Fig. $1 A$ ). Indeed, a $\mathrm{Vpr}$ concentration-dependent effect was observed in terms of a reduction in whole-cell currents in dissociated neurons (Fig. $1 B$ ). When the high-conductance $\mathrm{Ca}^{2+}$-activated $\mathrm{K}^{+}$channels (BK channels) were inhibited with iberiotoxin (25 nM), the Vprinduced reduction in current was significantly blocked (Fig. 1C, inset represents results from five cells). $\mathrm{Vpr}(10 \mathrm{nM})$ also caused a reduction in the delayed rectifier $\left(I_{\mathrm{K}}\right)$ potassium current (Fig. $1 D$, top panel) but not the transient outward $\left(I_{\mathrm{A}}\right)$ potassium current (Fig. 1D, bottom panel). Thus, Vpr was found to induce rapid changes in neuronal membrane currents involving an inhibition of voltage-dependent potassium channels.

\section{HIV-1 Vpr in vivo expression and neurotoxicity}

Although Vpr is known to exert neuropathogenic actions and has been observed in the brain (Piller et al., 1998; Huang et al., 2000; 


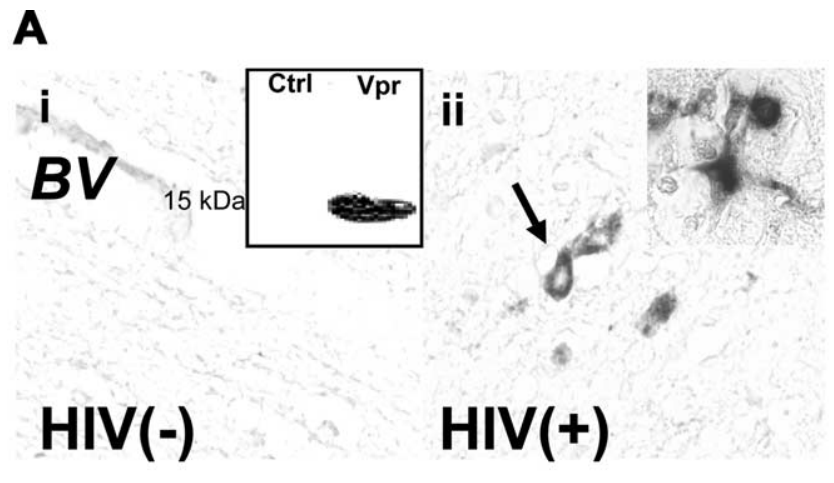

B
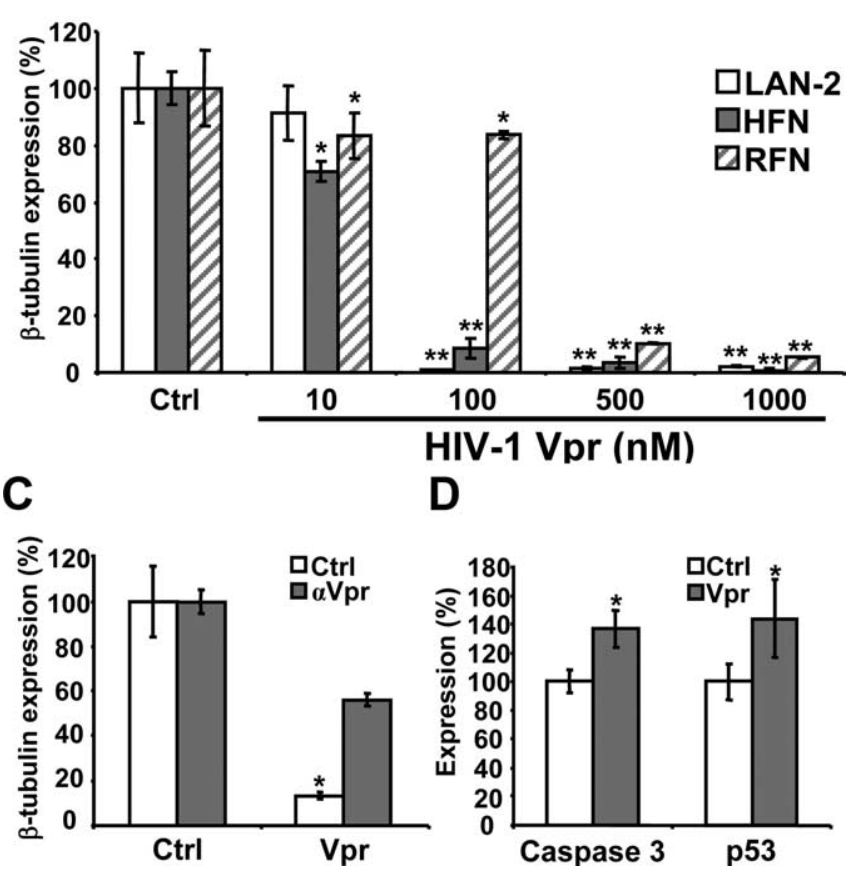

Figure 2. HIV-1 Vpr is expressed in brains of HIV-1-infected patients and induces neuronal cell death. $\boldsymbol{A}$, Detection of recombinant HIV-1 Vpr using an anti-Vpr polyclonal antibody on Western blot (Ai, inset). HIV-1 Vpr immunoreactivity was absent in brain sections from HIV-1 uninfected controls (Ai). Conversely, Vpr was detectable in brain sections from HIV-1-infected patients in perivascular and parenchymal cells (Aii, arrow) (magnification, 40X). These cells resembled monocytoid cells and coexpressed $C D 45$, whereby Vpr was stained brown (DAB) and CD45 was stained purple (BCIP) (Aii, inset) (magnification, 100X). (BV, blood vessel). Ctrl, Control. $\boldsymbol{B}, \beta$-Tubulin expression in human neurons: LAN-2 cholinergic cell line, HFNs, and RFNs treated with increasing concentrations of HIV-1 Vpr for $48 \mathrm{~h}$, showing a concentrationdependent reduction in neuronal viability as evidenced by reduced $\beta$-tubulin immunoreactivity. C, $\beta$-Tubulin expression in LAN-2 cells with or without HIV-1 Vpr (100 nM) treatment, with and without anti-HIV-1 Vpr antibodies for $48 \mathrm{~h}$, showing that pretreatment with the antibody rescued neurons from Vpr-mediated neurotoxicity. D, Active caspase-3 and total $p 53$ expression was increased in LAN-2 cells treated with $100 \mathrm{~nm}$ Vpr for $24 \mathrm{~h}$. Values were normalized to the $\beta$-tubulin immunoreactivity and expressed as the percentage increase relative to control cells $\left({ }^{*} p<0.05 ;{ }^{* *} p<0.01\right)$.

Patel et al., 2000, 2002; Sabbah and Roques, 2005; Wheeler et al., 2006), the extent of Vpr detection in the brain is unknown. Hence, we examined Vpr expression in brains from HIV-1infected and uninfected persons using a polyclonal antibody, which specifically recognized HIV-1 Vpr (Fig. 2Ai, inset). Vpr immunoreactivity was not present in sections from HIV-1 uninfected brains (Fig. $2 \mathrm{Ai}$ ). However, in brain sections from HIV-1infected patients, $\mathrm{Vpr}$ immunoreactivity was detectable in perivascular and parenchymal cells that resembled monocytoid cells (Fig. 2Aii). Furthermore, at higher magnification, we observed that Vpr immunoreactivity was colocalized with CD45 immunoreactivity showing brown and purple immunostaining, respectively, in brain sections from HIV-1 infected brains (Fig. $2 \mathrm{Aii}$, inset). Moreover, we also examined the presence of $\mathrm{Vpr}$ transcripts in the brains of HIV-1-infected patients $(n=35)$ by a nested RT-PCR protocol, which indicated that Vpr encoding RNA was present in $42 \%$ of brains analyzed (data not shown). Hence, Vpr was expressed in the brains of patients with HIV-1 infection, chiefly in monocytoid cells.

Given that Vpr is a secreted protein, detected in both serum and CSF (Levy et al., 1994), we next investigated its effects on a human cholinergic neuronal cell line (LAN-2) as well as primary human and rat fetal neurons. Soluble Vpr was neurotoxic in a concentration-dependent manner, as indicated by loss of $\beta$-tubulin expression (Fig. $2 B$ ) with the extent of neurotoxicity hinging on the individual cell type. The LAN-2 and HFN cells exhibited greater vulnerability to $\mathrm{Vpr}$-mediated neurotoxicity at $100 \mathrm{nM}$ compared with RFN, where there was evident neuronal injury occurring at $500 \mathrm{~nm}$ (Fig. 2 B). Importantly, the neurotoxic effects of $\mathrm{Vpr}$ were reduced by immunoabsorption of $\mathrm{Vpr}$ with an anti-Vpr polyclonal antibody in both Vpr treated (100 nM) and untreated (Fig. 2C). HIV-1 Vpr neurotoxicity in LAN-2 cells was also confirmed using a trypan blue exclusion assay to assess cell membrane integrity, indicating that increased neuronal death was observed at both $10 \mathrm{~nm}(14 \%)$ and $100 \mathrm{~nm}(39 \%)$ normalized to PBS-treated (control) cells (data not shown). To pursue the mechanism by which neurons were injured by $\mathrm{Vpr}$, we assayed activated or C-Casp-3 expression (normalized to $\beta$-tubulin expression), revealing augmented expression in Vpr-treated neurons (Fig. 2D). Complementing these latter findings, neuronal p53 expression was also elevated in neurons after Vpr treatment, suggesting that apoptosis was the underlying process that caused neuronal damage (Fig. 2D).

\section{HIV-1 Vpr mediates neuronal apoptosis through activated caspase- 9}

Because activation of BK channels and caspase- 3 are involved in the apoptosis signaling pathway (Liang et al., 2005), we next investigated the effects of HIV-1 Vpr on the "upstream" events, eventually leading to caspase- 3 activation. Because increased cleaved caspase-3 expression was only observed in neuronal cells treated with $100 \mathrm{~nm} \mathrm{HIV-1} \mathrm{Vpr} \mathrm{(Fig.} \mathrm{1D),} \mathrm{we} \mathrm{used} \mathrm{this} \mathrm{"neuro-}$ toxic" concentration in the next series of experiments. It is well established that p53 can mediate the "intrinsic" apoptosis pathway (for review, see Giaccia and Kastan, 1998), and thus we examined whether Vpr-induced neuronal cell death was mediated through this pathway. Mitochondrial membrane permeability was assessed with the cyanine dye $\operatorname{DiIC}_{1}(5)$, which accumulates in mitochondria with active membrane potentials (Shapiro et al., 1979). In contrast to the controls, $\mathrm{DiIC}_{1}(5)$ staining intensity diminished when neuronal cells were treated with cyanide 3-chlorophenylhydrazone (CCCP), a reagent that disrupts the mitochondrial membrane potential, resulting in an increased percentage of LAN-2 cells with low $\operatorname{DilC}_{1}(5)$ staining (Fig. 3A). Exposure of neuronal cells to low concentrations of $\operatorname{Vpr}(0.1-10$ nM) had no effect on the mitochondrial membrane potential (Fig. $3 A, B)$. However, after $4 \mathrm{~h}$ of exposure to a neurotoxic concentration of $\mathrm{Vpr}(100 \mathrm{nM})$, there was an approximate sixfold increase in the percentage of neuronal cells showing diminished $\mathrm{DiIC}_{1}(5)$ staining compared with untreated cells (Fig. $3 \mathrm{~A}, \mathrm{C}$ ). Indeed, the proportion of neuronal cells showing diminished $\mathrm{DiIC}_{1}(5)$ staining after $\mathrm{Vpr}$ exposure approached that of the pos- 
A

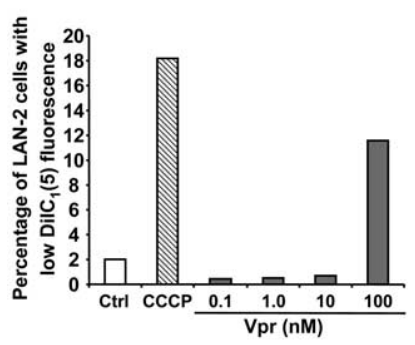

C

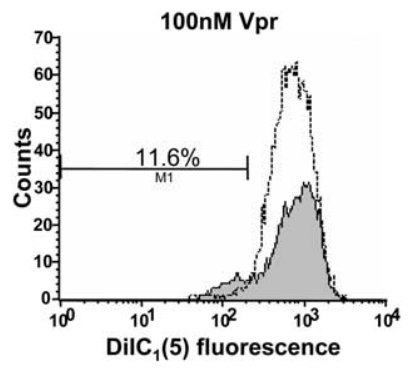

E

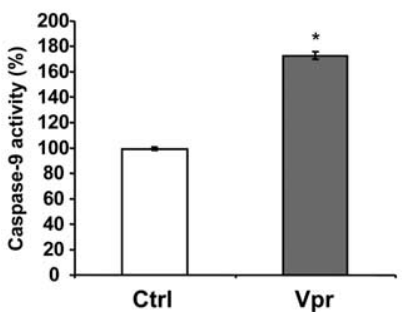

B

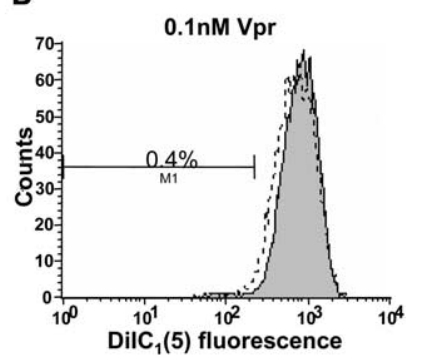

D

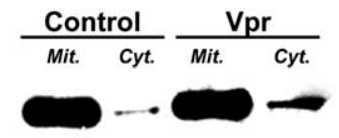

$\mathbf{F}$

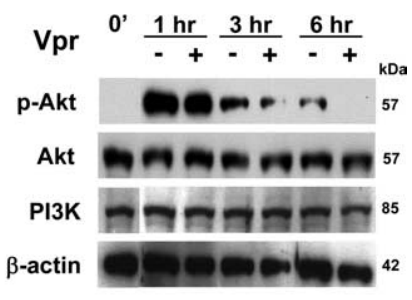

Figure 3. HIV-1 Vpr induces the intrinsic apoptosis pathway in neuronal cells. $A-C, D_{1} C_{1}(5)$ staining in LAN-2 cells pretreated with Vpr. $A$, Percentage of LAN-2 with reduced DilC $C_{1}(5)$ staining. $\boldsymbol{B}, \boldsymbol{C}$, Individual DilC $C_{1}(5)$ fluorescence plots are shown for LAN-2 cells treated with 0.1 nм $\operatorname{Vpr}(\boldsymbol{B})$ and $100 \mathrm{~nm} \operatorname{Vpr}(\boldsymbol{C})$ (solid line represents Vpr-treated cells; dotted line represents control treated cells). $M 1$ region represents the percentage of $\mathrm{LAN}_{2} 2$ cells with reduced DilC $\mathrm{C}_{1}(5)$ expression (data summarized in $\boldsymbol{A}$ ). $\boldsymbol{D}$, Increased cytochrome c immunoreactivity was present in the cytosolic fraction from LAN-2 cells pretreated with Vpr compared with control (Mit denotes mitochondrial fraction; (yt denotes cytosolic fraction). $\boldsymbol{E}$, Enhanced caspase-9 activity was evident in lysates from LAN-2 cells treated with HIV-1 Vpr. F, Phosphorylated Akt (p-Akt), total Akt, $\mathrm{PI} 3 \mathrm{~K}$, and $\beta$-actin immunoreactivity in lysates prepared from LAN-2 cells cultured with or without Vpr for up to $6 \mathrm{~h}$, showing downregulation of $p$-Akt. $\left({ }^{*} p<0.001\right)$. Ctrl, Control.

itive control CCCP. In addition to increased mitochondria membrane permeability, neuronal cells cultured in the presence of $\mathrm{Vpr}$ demonstrated greater cytochrome $c$ immunoreactivity in cytosolic fractions compared with untreated controls (Fig. 3D). Caspase- 9 activity was significantly higher in lysates prepared from neuronal cells, which had been cultured in the presence of HIV-1 Vpr, compared with untreated controls (Fig. 3E). These latter studies were supported by reduced phosphorylated Akt expression in neurons after Vpr exposure compared with induction of phosphorylated Akt in untreated cells because of culture medium change, whereas total Akt and PI3K were unaffected by Vpr application (Fig. $3 F$ ). Together, these results suggested that induction of the intrinsic apoptosis pathway, including increased mitochondria membrane permeability, cytochrome $c$ release, caspase- 9 activation, and reduced phosphorylated Akt, participated in Vpr-mediated neurotoxicity.

\section{HIV-1 Vpr exerts cell type-dependent immunogenic and neurotoxic effects}

In addition to the direct neurotoxic effects of HIV-1 viral proteins, neuronal apoptosis may also result indirectly because of neurotoxic factors secreted by brain resident non-neuronal cells in response to stimulation by viral proteins (for review, see Jones and Power, 2006). To investigate potential indirect mechanisms of Vpr-mediated neurotoxicity, supernatants from HIV-1 Vprstimulated astrocytic cells were applied to neuronal cells. As determined by $\beta$-tubulin expression, no neurotoxicity was observed with supernatants from astrocytic (U373) cells stimulated with $10 \mathrm{~nm}$ Vpr or less (Fig. 4A). Indeed, at these Vpr concentrations, there appeared to be a modest concentration-dependent increase in $\beta$-tubulin expression, which was abrogated in the presence of $\mathrm{Vpr}$-specific antibodies. However, conditioned media from astrocytic cells stimulated with $100 \mathrm{~nm} \mathrm{Vpr}$ induced marked neuronal cell death, which was not reversed by Vprspecific antibodies. Immune dysregulation within the CNS is a cardinal feature of HIV-1 infection and is assumed to contribute to reduced neuronal viability through the secretion of neurotoxic molecules. Compared with unstimulated controls, IL- $1 \beta$ transcript levels were reduced in Vpr-stimulated astrocytic cells in a concentration-dependent manner (Fig. 4B). In contrast, IL-6 was increased in Vpr-treated astrocytic cells, although this finding was apparent at $100 \mathrm{~nm}$ only (Fig. 4C). Indirect neurotoxicity also was evident when monocytoid cells (U-937) were stimulated with as low as $0.1 \mathrm{~nm} \mathrm{Vpr}$, although the maximal effect was seen when monocytoid cells were stimulated with $100 \mathrm{~nm}$ Vpr. Regardless of the Vpr concentration used, previous treatment of neuronal cells with $\mathrm{Vpr}$-specific antibodies failed to abrogate the neurotoxicity of Vpr-activated monocytoid cell-derived supernatants (Fig. 4D). In monocytoid cells, soluble $\mathrm{Vpr}$ induced IL- $1 \beta$ transcript abundance (Fig. $4 E$ ), whereas IL-6 expression was markedly reduced in a concentration-dependent manner (Fig. 4F). These studies suggested that soluble Vpr influenced glial cell immune responses, which was accompanied by the secretion of cellular neurotoxins depending on the individual cell type that was stimulated by Vpr.

\section{In vivo $\mathrm{HIV}-1 \mathrm{Vpr}$ expression results in neurotoxic and neuroimmune effects}

Although soluble Vpr exerted immunogenic and neurotoxic properties in different assays of neural function, the in vivo neurotoxic effects of $\mathrm{Vpr}$ expression in monocytoid cells are unknown. To investigate this question, we examined transgenic mice expressing HIV-1 (NL4-3) Vpr under the control of the $c$-fms promoter $(\mathrm{Tg})$, which drives transgene expression in monocytoid cells, together with littermate wild-type controls (Fig. 5A). Macrophages from $\mathrm{Tg}$ and $\mathrm{Wt}$ mice showed that $\mathrm{Vpr}$ transcripts were detected in $\mathrm{Tg}$ but not $\mathrm{Wt}$ animals (Fig. $5 B$, inset). In fact, supernatants from $\mathrm{Vpr}$ Tg-derived macrophages were highly neurotoxic to RFNs, which was prevented by pretreatment with the anti-Vpr antibody (Fig. 5B). Likewise, soluble Vpr was neurotoxic to RFNs when added to supernatants from Wt-derived macrophages but again was reversed by pretreatment with the anti-Vpr antibody (Fig. 5B). To investigate further the effects of Vpr in the brain, we initially examined Vpr transcript levels, disclosing that Vpr was present in the basal ganglia (BG) of Vpr Tg animals but not in Wt littermates (Fig. 5C, inset). Vpr transcripts were also detected in the cortex (CTX) and hindbrain (HB) of these animals, although higher Vpr transcript levels were found in the BG and CTX compared with the HB (Fig. 5C). Of note, $\mathrm{Vpr}$ immunoreactivity was not present on Western blot using brain tissue from both $\mathrm{Tg}$ and $\mathrm{Wt}$ animals. Analysis of brains from $\mathrm{Vpr} \mathrm{Tg}$ and $\mathrm{Wt}$ animals revealed that there were no differences in F4/80 (a marker for activated macrophages), IL-1 $\beta$, or TNF- $\alpha$ transcript levels (Fig. $5 D$ ). In contrast, IL-6 transcript 
levels were significantly lower in the BG, CTX, and $\mathrm{HB}$ of Vpr Tg animals compared with Wt controls. These studies indicated that Vpr was expressed and secreted by monocytoid cells in Tg animals. Moreover, Vpr was expressed in the brains of Tg animals, which was accompanied by a marked reduction in IL-6 transcript levels, thereby recapitulating the effects of soluble Vpr in monocytoid cells (Fig. 4E).

Vpr causes in vivo neurodegeneration and neurobehavioral abnormalities

Although Vpr was expressed at the transcript level, it was critical to determine whether Vpr protein was present in the brains of the Tg mice. Hence, we investigated the presence of $\mathrm{Vpr}$ in the brains of $\mathrm{Tg}$ animals and $\mathrm{Wt}$ littermates, disclosing that Vpr immunoreactivity was absent in the brains of $\mathrm{Wt}$ littermate controls (Fig. $6 A$ ) but present in the brains of $\mathrm{Tg}$ animals (Fig. 6B). Furthermore, Vpr colocalized with F4/80 immunoreactivity, suggesting it was expressed principally in activated monocytoid cells in both perivascular (Fig. 6B) and parenchymal (Fig. 6B, inset) regions, whereas only F4/80 immunoreactivity was observed in the Wt sections. Analysis of Iba-1 immunoreactivity on monocytoid cells did not show substantial differences in microglia/macrophage morphology and numbers between Wt (Fig. 6C) and Tg animals (Fig. 6D). Conversely, NeuN exhibited reduced immunoreactivity in the Vpr Tg animals (Fig. 6F) compared with Wt controls (Fig. 6E), particularly in subcortical regions. Moreover, there was activated caspase- 3 immunoreactivity within neurons as shown by NeuN and cleaved caspase-3 double immunolabeling (Fig. 6F, inset). Given that we observed reduced NeuN immunoreactivity with increased activation of caspase-3 in Vpr Tg animals, we next investigated the expression of three representative neuronal proteins, GAD65 (GABAergic neurons), VAChT (cholinergic neurons), and synaptophysin (most synapses) in the brains of Tg and Wt animals by Western blotting, revealing that all three neuronal proteins were reduced in the basal ganglia of $\mathrm{Vpr} \mathrm{Tg}$ animals along with increased immunoreactivity of cleaved caspase- 3 relative to $\beta$-actin, which was slightly higher in $\mathrm{Vpr}$ Tg BG (Fig. 6G,H). However, the relative expression of GAD65 and VAChT was similar in the cerebral cortices of $\mathrm{Vpr} \mathrm{Tg}$ animals compared with $\mathrm{Wt}$ controls (Fig. 6I). Conversely, relative synaptophysin levels were significantly higher in the Tg animal cortices (Fig. 6I). Similar to the BG, the CTX also showed an increase in immunoreactivity of cleaved caspase-3 (Fig. 6I). Because Vpr expression was associated with neuronal injury in vivo and in vitro, we also examined the neurobehavioral effects of $\mathrm{Vpr}$ expression in the present transgenic line. These studies revealed that Vpr Tg animals exhibited abnormalities in neurobehavioral performance evidenced by the Tg animals being significantly more hyperexcitable compared with the Wt mice (Fig. 6J). Thus, these studies showed that Vpr was cytotoxic to subcortical neurons, together with exhibiting aberrant motor activity.

\section{Discussion}

Herein, we report for the first time that both HIV-1 Vpr-encoded proteins and transcripts were detectable in the brains of HIV-1
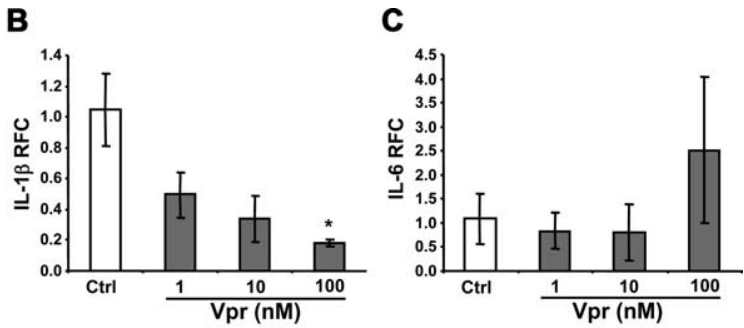

E
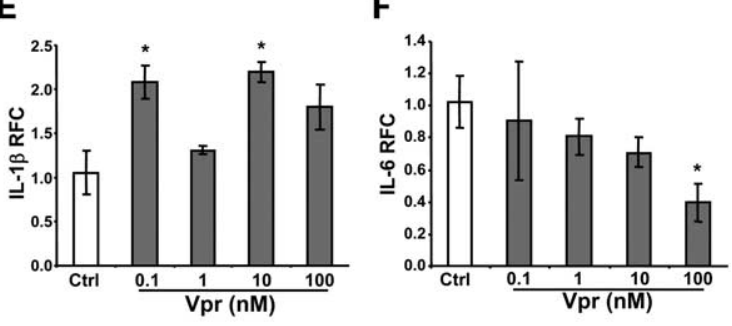

Figure 4. HIV-1 Vpr exerts cell type-dependent immunogenic and neurotoxic effects. $A, D$, LAN-2 cells were cultured in the poststimulation with soluble Vpr. Data represent mean ( \pm SEM) from a minimum of three replicates and are expressed relative to $\left.{ }^{* * *} p<0.001\right)$

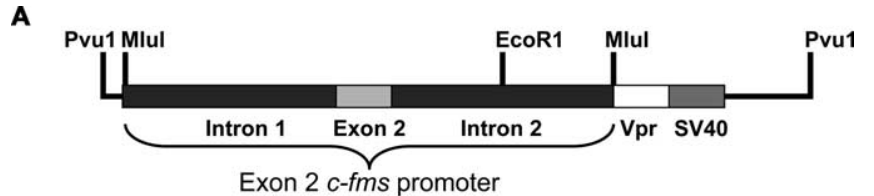

B Vpr Supernatant

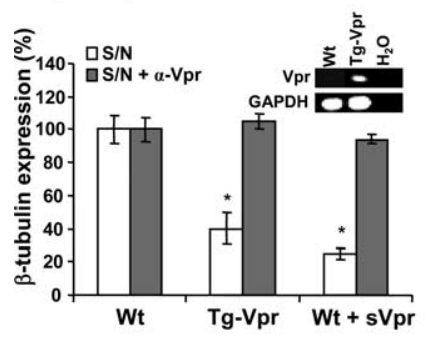

C

D

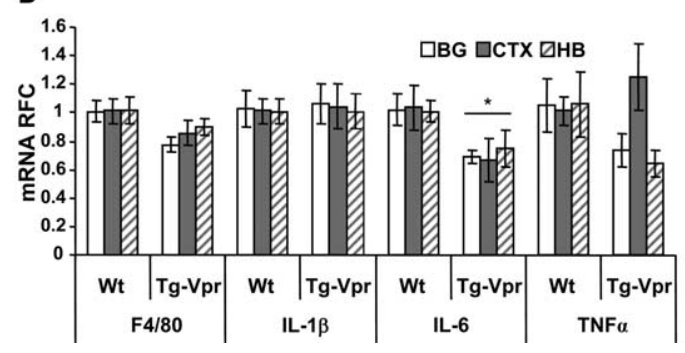

Figure 5. HIV-1 Vpr expression and secretion by monocytoid cells in Tg animals. A, Schematic figure of the HIV-1 Vpr transgene expressed under the control of exon 2 of the c-fms promotor. $\boldsymbol{B}$, Vpr transcripts were detected in macrophages from Vpr Tg animals but not in Wt littermate controls (inset). RFNs were cultured with supernatants from either Vpr Tg macrophages, Wt macrophages, or Wt macrophages supplemented with soluble HIV-1 Vpr and pretreated with or without anti-Vpr antibodies, and $\beta$-tubulin expression was evaluated after $48 \mathrm{~h}$. C, Greater levels of Vpr transcripts were detected in the BG and CTX compared with the HB in Vpr Tg animals. The inset depicts the detection of HIV-1 Vpr-specific transcripts in the BG of four Vpr Tg animals. D, F4/80, IL- $\beta$, IL-6, and TNF- $\alpha$ transcript levels in the BG, CTX, and HB did not change between Wt and Vpr Tg animals except for IL-6 levels ( $\left.{ }^{*} p<0.05 ;{ }^{* *} p<0.01\right)$. 

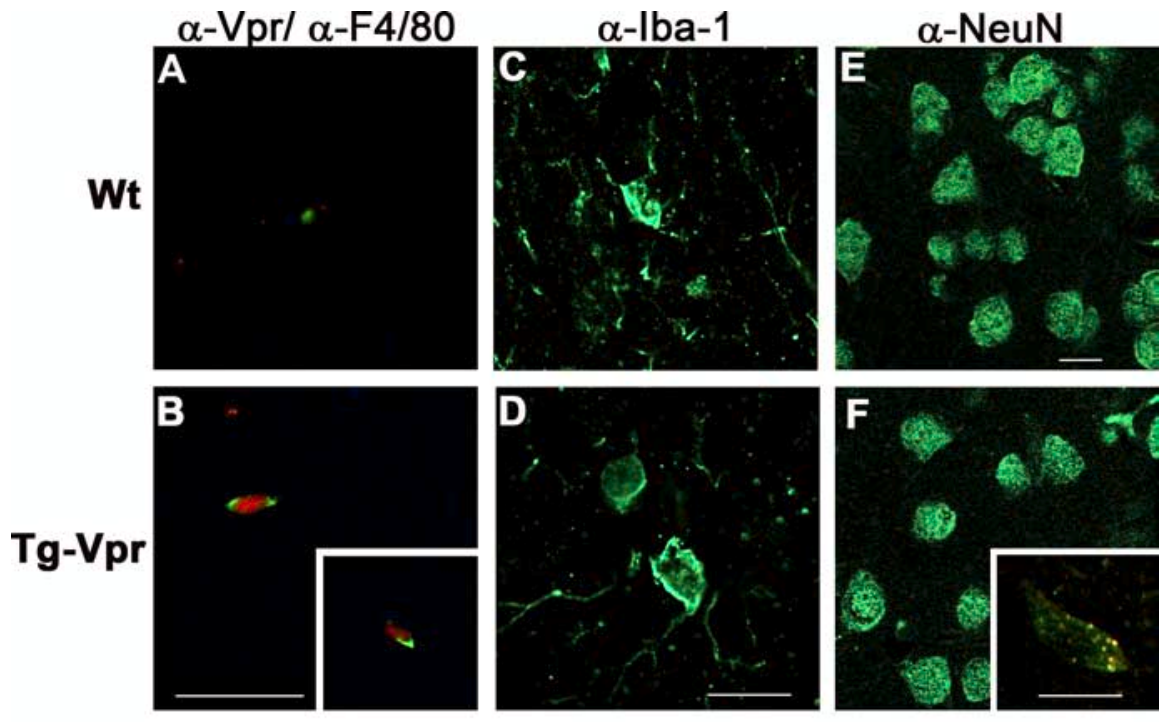

G

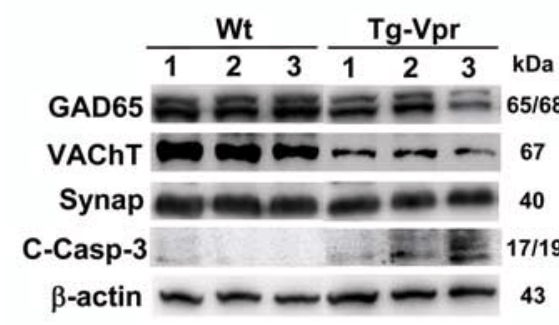

I

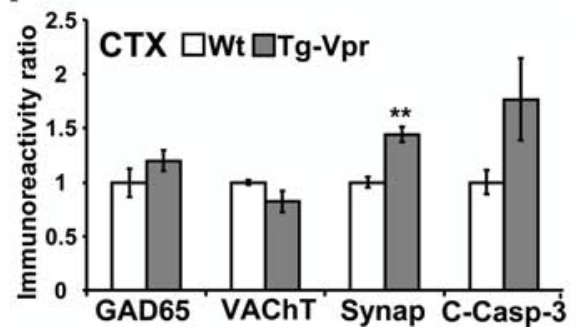

H

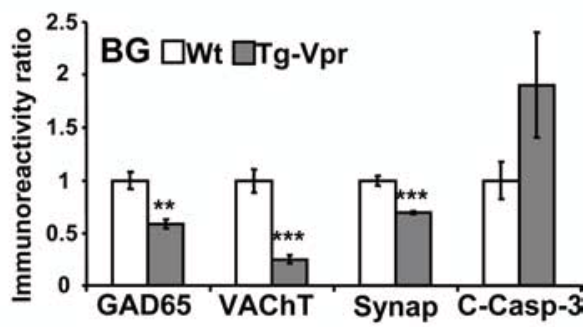

J

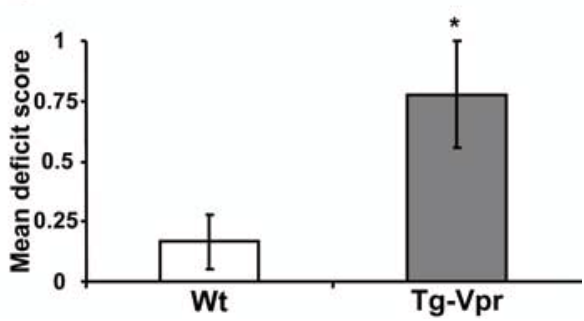

Figure 6. HIV-1 Vpr expression in the brain of Vpr Tg animals is accompanied by neuronal cell loss. $\boldsymbol{A}, \boldsymbol{B}$, HIV-1 Vpr immunoreactivity (red) was not detected in the brains of Wt littermate controls $(\boldsymbol{A})$ but was observed in Vpr-Tg animals that colocalized with F4/80 immunoreactivity (green) in the perivascular cells $(\boldsymbol{B})$ and parenchymal cells ( $\boldsymbol{B}$, inset). $\boldsymbol{C}, \boldsymbol{D}$, Iba- 1 immunoreactivity in monocytoid cells in Wt $(\boldsymbol{C})$ and $\operatorname{Tg}(\boldsymbol{D})$ animals did not differ. $\boldsymbol{E}, \boldsymbol{F}$, However, NeuN immunoreactivity in neurons of the basal ganglia of Wt littermate controls $(\boldsymbol{E})$ was substantially greater than NeuN immunoreactivity in the BG of Vpr-Tg animals $(\boldsymbol{F})$ with an increase in cleaved caspase-3 (red) colocalizing with NeuN (green; $\boldsymbol{F}$, inset). G, GAD65, VAChT, and synaptophysin immunoreactivity was reduced, whereas there was an increase in cleaved caspase-3 in the basal ganglia of Vpr Tg compared with Wt animals. $\boldsymbol{H}$, Graphic analysis of GAD65, VAChT, and synaptophysin immunoreactivity in the basal ganglia disclosed all proteins were suppressed in Tg animals compared with Wt littermates, whereas cleaved caspase-3 was increased. I, Conversely, GAD65 and VAChT expression relative to $\beta$-actin immunoreactivity did not differ between Wt and Tg animals, whereas both synaptophysin and cleaved caspase-3 expression in the cerebral cortex was higher in Wt animals. J, Vpr Tg animals exhibited marked deficits in neurobehavioral performance compared with Wt littermates at 14 weeks of age $\left({ }^{*} p<0.05 ;{ }^{* *} p<0.01\right)$. Scale bars, $15 \mu \mathrm{m}$. jury. The present observations underscore the neuropathogenic effects exerted by Vpr, including its ability to exert both direct cytotoxic actions on neurons but also activate glia resulting in the release of neurotoxic molecules. In fact, our results in the Vpr Tg mice recapitulate the findings of subcortical neuronal damage and neurobehavioral disturbances in patients with HAD. Hence, Vpr might serve as a putative target for future therapeutic interventions in the treatment of HIV-related neurological disorders.

The mechanisms underlying neuronal injury and death in HIV-mediated neurodegeneration remain controversial, although apoptosis is a recognized component (for review, see Jones and Power, 2006). The present study demonstrates that Vpr-mediated neuronal cell death is accompanied by loss of mitochondrial membrane permeability, enhanced cytosolic levels of cytochrome $c$, and induction of caspase- 9 activity, all hallmarks of the intrinsic apoptosis pathway. The intrinsic apoptosis pathway can be initiated by a variety of external and/or internal signals that result in mitochondrial dysfunction. Of particular importance to neuronal survival is the maintenance of intracellular calcium homeostasis; during cytosolic calcium overload, disruption of the mitochondrial membrane results in the release of pro-apoptotic factors into the cytosol (Petersen et al., 2000). Indeed, our findings involving changes in calciumdependent BK channels indicate a link between the calcium mobilization and activation of caspase 9. Moreover, the changes in BK channels complement the observation that Vpr treatment results in neuronal excitation (data not shown), thereby reflecting changes in membrane potentials induced by $\mathrm{Vpr}$ in previous reports (Piller et al., 1998). However, it is a delicate balance between the actions of the pro-apoptotic and anti-apoptotic members of the Bcl-2 family of proteins, which regulate the induction of mitochondrial dysfunction. Nonetheless, it is widely recognized that stabilization of the tumor suppressor gene, p53, in response to celluseropositive patients, particularly in monocytoid cells. Treatment of neurons with soluble $\mathrm{Vpr}$ resulted in a direct effect on ionic conductance in neurons with rapidly ensuing changes in neuronal membrane potentials, together with the induction of the intrinsic apoptosis pathway in neurons. In addition to this direct Vpr-mediated neurotoxicity occurring in multiple neuronal cell types, Vpr application to glial cells also induced the secretion of cellular neurotoxins, which was evident for supernatants derived from Vpr-treated glial cells (Fig. 4A,D). Furthermore, transgenic expression of HIV-1 Vpr in mouse brain monocytoid cells, was accompanied by abnormalities in motor tasks and neuronal in- lar stress (e.g., DNA damage or hypoxia) results in apoptosis (for review, see Giaccia and Kastan, 1998). This response occurs, in part, through p53-mediated transcription of pro-apoptotic genes (e.g., Bax, Bak, Noxa, and Puma) (Oda et al., 2000; Wei et al., 2001; Yu et al., 2003), as well as transcriptional suppression of anti-apoptotic genes (e.g., Bcl-2 and survivin) (Hoffman et al., 2002). As our results demonstrated that elevated levels of neuronal p53 accompanied HIV-1 Vpr-induced neurotoxicity, it is interesting to speculate that this may be the initiating factor for the disruption of mitochondrial membrane potentials, release of cytochrome $c$, and subsequent caspase activation. However, how 
HIV-1 Vpr leads to p53 stabilization remains to be determined. Several possible mechanisms may exist, including the following: (1) p53 stabilization in neurons in response to Vpr-induced cellular stress; (2) induction of p53 transcription by HIV-1 Vpr; or (3) Vpr-mediated disruption of negative regulators of p53 (e.g., MDM2).

In addition to p53 stabilization, HIV-1 Vpr may induce the intrinsic apoptosis pathway via direct interactions with the mitochondrial membrane. Initial studies in yeast demonstrated that HIV-1 Vpr directly interacts with mitochondria (Jacotot et al., 2000). Furthermore, in mammalian cells and in isolated mitochondria, synthetic Vpr peptides directly bind to the adenine nucleotide translocator (ANT), a component of the mitochondria permeability transition pore located on the inner mitochondrial membrane, resulting in a decrease in mitochondria membrane potential and cytochrome $c$ release (Jacotot et al., 2001). Although synthetic peptides spanning the C-terminal domain of Vpr (residues 52-96 or 70-96) induced apoptosis in cultured rat cortical and striatal neurons, a synthetic Vpr peptide (residues 71-82) with known toxicity to isolated mitochondria did not induce neuronal cell death (Sabbah and Roques, 2005). Thus, direct interactions between Vpr and ANT alone may not be sufficient to induce the intrinsic apoptosis pathway specifically in neurons.

Surprisingly, in vivo Vpr-mediated neuronal cell death occurred in the absence of profound microglia activation, which is usually a feature of HIV-1 infection of the brain (for review, see Jones and Power, 2006); nonetheless, associated inflammation is not usually a feature of apoptosis. The in vivo expression of Vpr in the brains of mice failed to enhance both pro-inflammatory gene expression and F4/80 expression (a marker of activated microglia). There are conflicting published data with regard to the effects of $\mathrm{Vpr}$ on the expression of inflammatory cytokines (Ayyavoo et al., 1997; Roux et al., 2000). An anti-inflammatory effect of Vpr is thought to be mediated in part through coactivation of the human glucocorticoid receptor II complex (GR) (Kino et al., 1999). Indeed, Ayyavoo et al. (1997) demonstrated that $\mathrm{Vpr}$ inhibited the NF- $\kappa \mathrm{B}$ driven transcription of a reporter gene, which was accompanied by increased $I \kappa \mathrm{B}$ transcription. Thus, Vpr might mimic glucocorticoid effects on suppression of inflammation through induction of $I \kappa \mathrm{B}$ transcription, depending on the individual target cell. In addition, the Vpr-GR complex is necessary and sufficient to recruit the NF- $\kappa \mathrm{B}$ coactivating protein poly(ADP-ribose) polymerase-1, thus preventing its nuclear localization and coactivation of NF- $\kappa \mathrm{B}$ (Muthumani et al., 2006). Thus, Vpr might cause the apoptosis observed in the brains of individuals with HAD, whereas other viral proteins (e.g., gp120, Tat, and gp41) dictate the extent of immune activation, as suggested by previous studies (for review, see Jones and Power, 2006).

Despite the variable effects of soluble Vpr on astrocytic and monocytoid cells, transgenic expression of $\mathrm{Vpr}$ in monocytoid cells resulted in neuropathogenic outcomes as evidenced by reduced IL-6 transcript expression and neuronal injury in vivo. It is also plausible that the reduction in IL-6 expression might result in the aberrant synaptic scaling, given the neurotrophic effects of IL- 6 and the recent demonstration of synaptic scaling mediated by TNF- $\alpha$ (Stellwagen and Malenka, 2006). Indeed, the present neurotoxic effects were also observed in vitro, although they could not be blocked by prototypic neuroprotective agents, including an adenosine $\mathrm{A}_{1}$ receptor agonist, the tetracycline, minocycline, or the antioxidant, ferulic acid (data not shown). Identification of the Vpr receptor on neurons and glia awaits future studies. Nevertheless, the present studies indicate that the neurotoxic effects of $\mathrm{Vpr}$ extend to different neuronal subpopulations, especially in the basal ganglia in conjunction neurobehavioral abnormalities, primarily defined by aberrant motor activity, whereas neuronal injury was not observed in the cortex and cerebellum (data not shown). In fact, synaptophysin immunoreactivity was higher in the cerebral cortices of Tg animals, in keeping with studies showing higher densities of synaptic boutons in animals chronically treated with neurotoxins such as cocaine (Robinson et al., 2001). Herein, Vpr expression was highest in the cortex and basal ganglia, likely reflecting higher densities of microglia and perivascular macrophages in these regions (Lawson et al., 1990). These latter findings recapitulate observations in humans, macaques, and cats infected with HIV-1, SIV, or FIV, respectively, in which virus is principally detected in the basal ganglia and cerebral (frontal) cortices with accompanying neuronal injury in these same regions (Everall et al., 1993; Fuller et al., 2004). Thus, the present model provides a unique opportunity to study neuronal death in vitro and in vivo in the absence of chronic innate immune activation in specific regions of the brains, while also offering a new model for testing therapies targeting HIVrelated neurodegeneration.

\section{References}

Adle-Biassette H, Levy Y, Colombel M, Poron F, Natchev S, Keohane C, Gray F (1995) Neuronal apoptosis in HIV infection in adults. Neuropathol Appl Neurobiol 21:218-227.

An SF, Giometto B, Scaravilli T, Tavolato B, Gray F, Scaravilli F (1996) Programmed cell death in brains of HIV-1-positive AIDS and pre-AIDS patients. Acta Neuropathol (Berl) 91:169-173.

Ayyavoo V, Mahboubi A, Mahalingam S, Ramalingam R, Kudchodkar S, Williams WV, Green DR, Weiner DB (1997) HIV-1 Vpr suppresses immune activation and apoptosis through regulation of nuclear factor kappa B. Nat Med 3:1117-1123.

Cohen EA, Terwilliger EF, Jalinoos Y, Proulx J, Sodroski JG, Haseltine WA (1990) Identification of HIV-1 vpr product and function. J Acquir Immune Defic Syndr 3:11-18.

Dickie P, Roberts A, Uwiera R, Witmer J, Sharma K, Kopp JB (2004) Focal glomerulosclerosis in proviral and c-fms transgenic mice links Vpr expression to HIV-associated nephropathy. Virology 322:69-81.

Emerman M (1996) HIV-1, Vpr and the cell cycle. Curr Biol 6:1096-1103.

Everall IP, Luthert PJ, Lantos PL (1993) Neuronal number and volume alterations in the neocortex of HIV infected individuals. J Neurol Neurosurg Psychiatry 56:481-486.

Fuller RA, Westmoreland SV, Ratai E, Greco JB, Kim JP, Lentz MR, He J, Sehgal PK, Masliah E, Halpern E, Lackner AA, Gonzalez RG (2004) A prospective longitudinal in vivo $1 \mathrm{H}$ MR spectroscopy study of the SIV/ macaque model of neuroAIDS. BMC Neurosci 5:10.

Gelbard HA, James HJ, Sharer LR, Perry SW, Saito Y, Kazee AM, Blumberg BM, Epstein LG (1995) Apoptotic neurons in brains from pediatric patients with HIV-1 encephalitis and progressive encephalopathy. Neuropathol Appl Neurobiol 21:208-217.

Giaccia AJ, Kastan MB (1998) The complexity of p53 modulation: emerging patterns from divergent signals. Genes Dev 12:2973-2983.

Guenther K, Deacon RM, Perry VH, Rawlins JN (2001) Early behavioural changes in scrapie-affected mice and the influence of dapsone. Eur J Neurosci 14:401-409.

He J, Choe S, Walker R, Di Marzio P, Morgan DO, Landau NR (1995) Human immunodeficiency virus type 1 viral protein $\mathrm{R}(\mathrm{Vpr})$ arrests cells in the G2 phase of the cell cycle by inhibiting p34cdc2 activity. J Virol 69:6705-6711.

Heseltine PN, Goodkin K, Atkinson JH, Vitiello B, Rochon J, Heaton RK, Eaton EM, Wilkie FL, Sobel E, Brown SJ, Feaster D, Schneider L, Goldschmidts WL, Stover ES (1998) Randomized double-blind placebocontrolled trial of peptide $\mathrm{T}$ for HIV-associated cognitive impairment. Arch Neurol 55:41-51.

Hoffman WH, Biade S, Zilfou JT, Chen J, Murphy M (2002) Transcriptional repression of the anti-apoptotic survivin gene by wild type p53. J Biol Chem 277:3247-3257. 
Huang MB, Weeks O, Zhao LJ, Saltarelli M, Bond VC (2000) Effects of extracellular human immunodeficiency virus type $1 \mathrm{vpr}$ protein in primary rat cortical cell cultures. J Neurovirol 6:202-220.

Jacotot E, Ravagnan L, Loeffler M, Ferri KF, Vieira HL, Zamzami N, Costantini P, Druillennec S, Hoebeke J, Briand JP, Irinopoulou T, Daugas E, Susin SA, Cointe D, Xie ZH, Reed JC, Roques BP, Kroemer G (2000) The HIV-1 viral protein $\mathrm{R}$ induces apoptosis via a direct effect on the mitochondrial permeability transition pore. J Exp Med 191:33-46.

Jacotot E, Ferri KF, El Hamel C, Brenner C, Druillennec S, Hoebeke J, Rustin P, Metivier D, Lenoir C, Geuskens M, Vieira HL, Loeffler M, Belzacq AS, Briand JP, Zamzami N, Edelman L, Xie ZH, Reed JC, Roques BP, Kroemer G (2001) Control of mitochondrial membrane permeabilization by adenine nucleotide translocator interacting with HIV-1 viral protein $r R$ and Bcl-2. J Exp Med 193:509-519.

Jassar BS, Ostashewski PM, Jhamandas JH (1997) GABA $_{\mathrm{A}}$ receptor modulation by protein tyrosine kinase in the rat diagonal band of Broca. Brain Res 775:127-133.

Jhamandas JH, MacTavish D (2004) Antagonist of the amylin receptor blocks $\beta$-amyloid toxicity in rat cholinergic basal forebrain neurons. J Neurosci 24:5579-5584.

Jhamandas JH, Cho C, Jassar B, Harris K, MacTavish D, Easaw J (2001) Cellular mechanisms for amyloid beta-protein activation of rat cholinergic basal forebrain neurons. J Neurophysiol 86:1312-1320.

Johnston JB, Jiang Y, van Marle G, Mayne MB, Ni W, Holden J, McArthur JC, Power C (2000) Lentivirus infection in the brain induces matrix metalloproteinase expression: role of envelope diversity. J Virol 74:7211-7220.

Jones G, Power C (2006) Regulation of neural cell survival by HIV-1 infection. Neurobiol Dis 21:1-17.

Jones G, Zhu Y, Silva C, Tsutsui S, Pardo CA, Keppler OT, McArthur JC, Power C (2005) Peripheral nerve-derived HIV-1 is predominantly CCR5-dependent and causes neuronal degeneration and neuroinflammation. Virology 334:178-193.

Kino T, Gragerov A, Kopp JB, Stauber RH, Pavlakis GN, Chrousos GP (1999) The HIV-1 virion-associated protein vpr is a coactivator of the human glucocorticoid receptor. J Exp Med 189:51-62.

Lavallee C, Yao XJ, Ladha A, Gottlinger H, Haseltine WA, Cohen EA (1994) Requirement of the Pr55gag precursor for incorporation of the Vpr product into human immunodeficiency virus type 1 viral particles. J Virol 68:1926-1934.

Lawson LJ, Perry VH, Dri P, Gordon S (1990) Heterogeneity in the distribution and morphology of microglia in the normal adult mouse brain. Neuroscience 39:151-170.

Levy DN, Refaeli Y, MacGregor RR, Weiner DB (1994) Serum Vpr regulates productive infection and latency of human immunodeficiency virus type 1. Proc Natl Acad Sci USA 91:10873-10877.

Liang F, Schulte BA, Qu C, Hu W, Shen Z (2005) Inhibition of the calciumand voltage-dependent big conductance potassium channel ameliorates cisplatin-induced apoptosis in spiral ligament fibrocytes of the cochlea. Neuroscience 135:263-271.

McArthur JC, Brew BJ, Nath A (2005) Neurological complications of HIV infection. Lancet Neurol 4:543-555.

Muthumani K, Choo AY, Zong WX, Madesh M, Hwang DS, Premkumar A, Thieu KP, Emmanuel J, Kumar S, Thompson CB, Weiner DB (2006) The HIV-1 Vpr and glucocorticoid receptor complex is a gain-offunction interaction that prevents the nuclear localization of PARP-1. Nat Cell Biol 8:170-179.

Oda E, Ohki R, Murasawa H, Nemoto J, Shibue T, Yamashita T, Tokino T, Taniguchi T, Tanaka N (2000) Noxa, a BH3-only member of the Bcl-2 family and candidate mediator of p53-induced apoptosis. Science 288:1053-1058.

Overbergh L, Valckx D, Waer M, Mathieu C (1999) Quantification of murine cytokine mRNAs using real time quantitative reverse transcriptase PCR. Cytokine 11:305-312.

Patel CA, Mukhtar M, Pomerantz RJ (2000) Human immunodeficiency virus type $1 \mathrm{Vpr}$ induces apoptosis in human neuronal cells. J Virol 74:9717-9726.

Patel CA, Mukhtar M, Harley S, Kulkosky J, Pomerantz RJ (2002) Lentiviral expression of HIV-1 Vpr induces apoptosis in human neurons. J Neurovirol 8:86-99.
Petersen A, Castilho RF, Hansson O, Wieloch T, Brundin P (2000) Oxidative stress, mitochondrial permeability transition and activation of caspases in calcium ionophore A23187-induced death of cultured striatal neurons. Brain Res 857:20-29.

Piller SC, Jans P, Gage PW, Jans DA (1998) Extracellular HIV-1 virus protein $R$ causes a large inward current and cell death in cultured hippocampal neurons: implications for AIDS pathology. Proc Natl Acad Sci USA 95:4595-4600.

Popov S, Rexach M, Ratner L, Blobel G, Bukrinsky M (1998) Viral protein R regulates docking of the HIV-1 preintegration complex to the nuclear pore complex. J Biol Chem 273:13347-13352.

Power C, McArthur JC, Nath A, Wehrly K, Mayne M, Nishio J, Langelier T, Johnson RT, Chesebro B (1998) Neuronal death induced by brainderived human immunodeficiency virus type 1 envelope genes differs between demented and nondemented AIDS patients. J Virol 72:9045-9053.

Power C, Henry S, Del Bigio MR, Larsen PH, Corbett D, Imai Y, Yong VW, Peeling J (2003) Intracerebral hemorrhage induces macrophage activation and matrix metalloproteinases. Ann Neurol 53:731-742.

Resnick L, Berger JR, Shapshak P, Tourtellotte WW (1988) Early penetration of the blood-brain-barrier by HIV. Neurology 38:9-14.

Robinson TE, Gorny G, Mitton E, Kolb B (2001) Cocaine selfadministration alters the morphology of dendrites and dendritic spines in the nucleus accumbens and neocortex. Synapse 39:257-266.

Roux P, Alfieri C, Hrimech M, Cohen EA, Tanner JE (2000) Activation of transcription factors NF-kappaB and NF-IL-6 by human immunodeficiency virus type 1 protein $\mathrm{R}$ (Vpr) induces interleukin-8 expression. J Virol 74:4658-4665.

Sabbah EN, Roques BP (2005) Critical implication of the (70-96) domain of human immunodeficiency virus type $1 \mathrm{Vpr}$ protein in apoptosis of primary rat cortical and striatal neurons. J Neurovirol 11:489-502.

Shapiro HM, Natale PJ, Kamentsky LA (1979) Estimation of membrane potentials of individual lymphocytes by flow cytometry. Proc Natl Acad Sci USA 76:5728-5730.

Spector SA, Hsia K, Pratt D, Lathey J, McCutchan JA, Alcaraz JE, Atkinson JH, Gulevich S, Wallace M, Grant I (1993) Virologic markers of human immunodeficiency virus type 1 in cerebrospinal fluid. The HIV neurobehavioral research center group. J Infect Dis 168:68-74.

Stellwagen D, Malenka RC (2006) Synaptic scaling mediated by glial TNFalpha. Nature 440:1054-1059.

Stewart SA, Poon B, Song JY, Chen IS (2000) Human immunodeficiency virus type $1 \mathrm{vpr}$ induces apoptosis through caspase activation. J Virol 74:3105-3111.

Subbramanian RA, Kessous-Elbaz A, Lodge R, Forget J, Yao XJ, Bergeron D, Cohen EA (1998) Human immunodeficiency virus type $1 \mathrm{Vpr}$ is a positive regulator of viral transcription and infectivity in primary human macrophages. J Exp Med 187:1103-1111.

Tsutsui S, Schnermann J, Noorbakhsh F, Henry S, Yong VW, Winston BW, Warren K, Power C (2004) $A_{1}$ adenosine receptor upregulation and activation attenuates neuroinflammation and demyelination in a model of multiple sclerosis. J Neurosci 24:1521-1529.

Wei MC, Zong WX, Cheng EH, Lindsten T, Panoutsakopoulou V, Ross AJ, Roth KA, MacGregor GR, Thompson CB, Korsmeyer SJ (2001) Proapoptotic BAX and BAK: a requisite gateway to mitochondrial dysfunction and death. Science 292:727-730.

Wheeler ED, Achim CL, Ayyavoo V (2006) Immunodetection of human immunodeficiency virus type 1 (HIV-1) Vpr in brain tissue of HIV-1 encephalitic patients. J Neurovirol 12:200-210.

Yao XJ, Mouland AJ, Subbramanian RA, Forget J, Rougeau N, Bergeron D, Cohen EA (1998) Vpr stimulates viral expression and induces cell killing in human immunodeficiency virus type 1-infected dividing Jurkat $\mathrm{T}$ cells. J Virol 72:4686-4693.

Yu J, Wang Z, Kinzler KW, Vogelstein B, Zhang L (2003) PUMA mediates the apoptotic response to p53 in colorectal cancer cells. Proc Natl Acad Sci USA 100:1931-1936.

Zhang K, Rana F, Silva C, Ethier J, Wehrly K, Chesebro B, Power C (2003) Human immunodeficiency virus type 1 envelope-mediated neuronal death: uncoupling of viral replication and neurotoxicity. J Virol 77:6899-6912. 